\title{
Imprensa de mulheres, imprensa para instruir mulheres: a atuação de Francisca Senhorinha da Motta Diniz no periódico O sexo feminino
}

\author{
PRESS FOR WOMEN, PRESS TO INSTRUCT WOMEN: THE PERFORMANCE OF FRANCISCA \\ SENHORINHA DA MOTTA DINIZ IN THE PERIODICAL O SEXO FEMININO
}

Dhttps://orcid.org/0000-0003-3790-8971 Aline de Souza de Souza Araújo França ${ }^{\text {A }}$

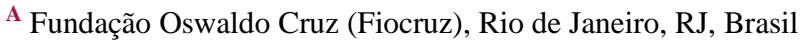

Recebido em: 30 abr. 2021 | Aceito em: 28 ag. 2021

Correspondência: Aline Araújo (aline.souza.araujo@outlook.com)

\begin{abstract}
Resumo
Este artigo tem como principal objetivo realizar um estudo acerca da atuação da professora e periodista Francisca Senhorinha da Motta Diniz, no sentido de sua agência como estimuladora da educação e instrução para mulheres no século XIX. Neste período, outros espaços, para além do ambiente escolar, se incumbiram da tarefa de propagar a educação e a instrução para diferentes setores da sociedade, entre estes as mulheres. A imprensa foi um destes caminhos pelos quais conhecimentos de distintas áreas do saber puderam ser propagados. No caso estudado, buscamos analisar a seção "Noticiario" do periódico O Sexo Feminino, publicado em Campanha da Princesa (MG) entre 1873-1874, posteriormente no Rio de Janeiro, em 1875 e 1889, buscando compreender as principais ideias e discursos acerca da educação para mulheres.
\end{abstract}

Palavras-chave: educação; mulheres; imprensa; vulgarização científica.

\begin{abstract}
This article has as main objective to carry out a study about the performance of professor and jornalista Franscisca Senhorinha da Motta Diniz, in the sense of her agency as a stimulator of eucation for women in the 19th century. In this period, ohter spaces, in addition to the school environment, took on the task of spreading instruction to diferente sectors of society, including women. The press was one of those paths through which knowledge could be propagated. In the case studied, we seek to analyze the "Noticiario" section of the jornal $O$ Sexo Feminino, published in Campanha da Princesa (MG) between 1873-1874, later in Rio de Janeiro, in 1875 and 1889, seeking to understand the main ideas and speeches about the education for women.
\end{abstract}

Keywords: education; women; press; scientific popularization. 


\section{Introdução}

A imprensa no Brasil começou a ser produzida de forma tardia. Foi somente com a vinda da família real que, de fato, teve início uma produção local, e ainda assim dentro dos limites impostos pela Coroa. Apenas com o afrouxamento da censura é que alguns jornais foram aparecendo, muitos deles dando ênfase a questões políticas. Foi apenas com a publicação de um decreto de dois de março de 1821 que a censura prévia foi suspensa. A partir daí, a liberdade de imprensa foi instalada no Brasil.

De acordo com Morel e Mariana Barros, essa liberdade teve avanços e recuos, neste sentido, não seguiu uma linha progressiva. Ainda assim, foi a partir do decreto de 1821 que teve início um movimento, no Brasil, de pluralidade com relação às formas de comunicação. De um modelo típico do Antigo Regime, que se utilizava "gazetas, pregões, bandos, exibição de cartazes impressos ou manuscritos nas ruas, leituras coletivas e proclamações em voz alta" (MOREL; BARROS, 2003, p. 24), para um espaço onde se consolidaram debates por meio da imprensa e onde "ganhavam importância as leituras privadas e individuais, permitindo a formação de uma opinião de caráter mais abstrato, fundada sobre o julgamento crítico de cada cidadão leitor e representando uma espécie de somatório das opiniões" (MOREL; BARROS, 2003, p. 24-25).

$\mathrm{O}$ assunto central dos primeiros anos da imprensa brasileira eram questões, em sua maioria, de cunho político. Na década de 1830 houve uma redução do número de periódicos, em decorrência das medidas adotadas pelo governo imperial. E, posteriormente, na década de 1870, houve um aumento significativo no aparecimento de diversos tipos de periódicos, que eram fundados com os mais diversos objetivos e interesses. As discussões políticas ainda continuaram aparecendo nos periódicos, porém só que não com a mesma ênfase da primeira metade do XIX.

Especialmente por essa época, apareceram jornais direcionados para diferentes públicos, como as mulheres, as crianças e os trabalhadores. No caso dos periódicos femininos, as mulheres entram em cena e passaram também a produzir e a escrever nos jornais. Visto como um espaço eminentemente masculino, aos poucos as mulheres começaram a se inserir e marcar lugar na imprensa, na qual procuraram tratar de diferentes assuntos e temas.

Este estudo se propõe a analisar a atuação de Francisca Senhorinha da Motta Diniz no jornal $O$ Sexo Feminino, a partir de uma perspectiva proposta por Ângela de Castro Gomes e Patricia Hansen ${ }^{\mathrm{i}}$ que pensa a figura do intelectual mediador. As autoras entendem o intelectual mediador como aquele cuja produção de conhecimentos e comunicação de ideias está, direta 
ou indiretamente, vinculada à perspectiva de uma intervenção político-social. Nesta direção, procuramos propor uma reflexão que pense Francisca Senhorinha a partir desta linha de análise. A partir da seleção de trechos publicados na seção "Noticiario", procuraremos comprovar que a atuação n'O Sexo Feminino de Francisca Senhorinha foi marcada pela preocupação em tornar a educação/instrução e a ciência acessíveis para a mulher.

\section{Imprensa, educação e vulgarização científica no século XIX}

No final do século XVIII surgiu, na França, um movimento no qual buscava tornar a educação e a instrução acessível a todos os indivíduos. Herdeiro do Iluminismo, esse movimento se espalhou para diversos lugares do mundo, inclusive o Brasil e foi denominado de vulgarização científica. Foi precisamente na segunda metade do século XIX, que pôde ser observada uma intensificação deste movimento aqui no Brasil. Por meio de diversas práticas, diversos indivíduos e instituições buscaram tornar o alcance da ciência e da educação mais amplo para todas as pessoas. Como herdeiro do Iluminismo, o movimento de vulgarização enxergava na educação e na ciência o caminho para a transformação. De acordo com Vergara:

Estes esforços de popularização partiam da premissa de que a ciência era a base da sociedade moderna e de que o Brasil deseja estar "ao nível de seu século" tinha que participar destas atividades divulgadoras que aconteciam nos principais centros ocidentais, tais como Estados Unidos, França, Alemanha e Inglaterra (VERGARA, 2008, p. 3).

As práticas da vulgarização científica se manifestavam de muitas formas: conferências, exposições, teatros, livros e, principalmente através da imprensa, pois a vulgarização pressupunha a ideia de que existia um aprendizado que não perpassava o ensino formal. Neste sentido, a prática da vulgarização científica perpassava a dimensão de um indivíduo, que será aqui denominado de mediador ou vulgarizador, que procurava traduzir o conhecimento para um público leigo. A relação entre público e ciência, neste contexto, era definida a partir da necessidade de tradução. E a maneira pela qual os mediadores ou vulgarizadores, buscavam provar a legitimidade do conhecimento era justamente demonstrando como a ciência poderia ser aplicada no cotidiano das pessoas.

Não se pode esquecer que o processo de vulgarização científica está relacionado com um contexto de aumento da produção de livros, manuais, jornais, revistas, bibliotecas, etc. Foi propriamente por conta da expansão do número de leitores que a vulgarização se tornou viável. A ciência tornou-se essencial ao progresso do país e ao bem-estar. 
A historiadora francesa Bernadette Bensaude-Vicente ${ }^{\mathrm{ii}}$ procurou investigar como o termo vulgarização surgiu no contexto francês do século XIX, apresentou os momentos e ações as quais podem ser identificados como seu auge e, posteriormente, a decadência das formas de vulgarização. A autora afirma que o vocábulo, na língua francesa, era utilizado para designar toda atividade de comunicação da ciência com o grande público. O termo, em certos momentos, adquiriu uma carga pejorativa, por remeter à ideia de vulgus. Entretanto, o movimento de vulgarização se fortaleceu ao longo do século XIX, a partir da expansão de livros, revistas, exposições, museus, cursos, baseados na concepção de uma 'ciência para todos'.

A noção que se defendia no século XIX era a de uma "ciência para todos". Essa concepção de que a ciência deveria ser amplamente divulgada, era baseada na noção iluminista de propagação das luzes. Vulgarizar os conhecimentos foi uma ideia que teve aceitação no período.

De acordo com Moema Vergaraiii, o termo vulgarização teve aparecimento no contexto francês de meados do século XIX e foi utilizado em um amplo movimento que no período visava tornar o alcance do conhecimento científico mais amplo. O termo pode ser definido, no século XIX, como "a ação de falar de ciência para os leigos" (VERGARA, 2003, p. 11). Por conta da influência que a cultura francesa exercia sobre o Brasil, o termo se tornou conhecido pelo público brasileiro a partir da ampliação das obras francesas. Até os anos 1930, a vulgarização no Brasil, era sinônimo de 'falar de ciência para leigos'. Após essa década, o vocábulo foi caindo em desuso por outro, a 'divulgação científica'.

Os vulgarizadores, ou mediadores, entendiam que o público leigo era composto por uma população que não era especialista, que não estava envolvida com a produção do conhecimento científico. Na época, este público era composto basicamente por mulheres, crianças e trabalhadores. Dado o grau de pouco letramento desta população no século XIX, os vulgarizadores se incumbiam da tarefa de traduzir os conhecimentos para uma linguagem na qual, independente do grau de instrução, todos pudessem compreender o conteúdo. Para isso, era utilizada uma linguagem mais amena, com textos mais curtos, e em alguns casos, a utilização de imagens.

A imprensa foi um dos meios pelos quais a ciência conseguiu, no século XIX, alcançar um público distinto, composto, na maior parte das vezes, por mulheres, crianças, trabalhadores, etc. Diversos jornais do período enfatizavam como a imprensa possuía uma missão de levar as 'luzes' para as populações. Essa missão estava atrelada a diversos aspectos que eram defendidos, como a ideia de que por meio da propagação da educação e da ciência poderia se 
engrandecer a nação, pois no pensamento da época, somente pela educação poderia se medir o desenvolvimento de um país.

Aliado a esse movimento de vulgarização dos conhecimentos, neste período do século XIX começou a ter início a expansão do mercado editorial, o que implicou no crescimento dos espaços reservados à leitura e venda de livros, como as bibliotecas e as livrarias, assim como no aumento do número de jornais e revistas dedicados a tratar sobre diversos temas, especialmente os literários, o que pôde tornar mais acessível a ideia de uma educação e instrução por meio da imprensa. Vinicius Gagliardo destaca como, aos poucos, vai se consolidando uma cultura letrada no Brasil, a partir do surgimento de instituições e espaços dedicados à divulgação do conhecimento:

No decorrer do século XIX também houve grande aumento das instituições e espaços de apoio às letras, às ciências e à cultura: livrarias, bibliotecas, gabinetes de leitura, sociedades e academias artísticas, literárias e científicas, colégios regulares e técnicos, seminários, faculdades (inicialmente as de Direito e Medicina), teatros, entre uma série de outros estabelecimentos que auxiliaram, ainda que lentamente, na transformação de uma sociedade extremamente oralizada para uma sociedade cada vez mais letrada, em que a palavra impressa conquistava mais espaço (GALIARDO, 2015, p. 129-130).

Boa parte dos editores e redatores de periódicos do século XIX, no Brasil, exaltava a imprensa como um mecanismo de difusão do conhecimento. Por conta do pouco acesso de grande parte da população ao conhecimento formal, os homens e as mulheres de letras se sentiam na obrigação de instruir a população por meio da palavra escrita, impressa nas revistas e nos jornais. A preocupação central era com a instrução pública do povo. Defendia-se que era necessário que o governo imperial investisse em maneiras de ampliar o acesso da população ao conhecimento, pois, na época, se entendia que progresso e instrução eram campos aliados e que, para o país poder desenvolver-se era vital o investimento em instrução.

Desse modo, desde sua gênese, no XIX, a imprensa brasileira se caracterizou por sua relação com a instrução, e operou de modo a tornar essa instrução acessível. Para os homens e as mulheres de letras que publicaram nos periódicos, a imprensa era um mecanismo de combate à ignorância e ao obscurantismo:

De acordo com a ampla gama de redatores e escritores que publicaram periódicos durante o século XIX, a instrução era considerada um mecanismo fundamental para se incutir novas ideias políticas, o que resultaria no abandono do mundo da ignorância em direção ao mundo da racionalidade, do esclarecimento e, no limite, da liberdade (GAGLIARDO, 2015, p.132). 
$\mathrm{O}$ auge da imprensa como instrumento pedagógico foi compreendido entre os anos de 1840 à década de 1870, que foi o período no qual diversos literatos atuaram como redatores e colaboradores em muitos periódicos da época ${ }^{\mathrm{iv}}$. Os periódicos foram, no século XIX, portanto, um dos principais meios de divulgação de ideias. Era principalmente através de jornais e revistas que as noções de nação, pátria, civilização, progresso, desenvolvimento, ciência, eram propagadas para o público. Ainda que não se tenham muitos meios de descobrir a relação entre público e periódicos no XIX, alguns indícios podem indicar as preferências do público. Exemplo disso são os jornais e revistas que tiveram longa duração, o que pode indicar a continuidade e aumento das assinaturas; além disso, os temas das revistas. Moda, por exemplo, era um assunto que tinha um expressivo espaço nos periódicos femininos, o que indicaria o gosto e escolha do público.

O discurso civilizatório divulgado pela imprensa dizia respeito tanto a questões públicas quanto à domésticas. Para civilizar a sociedade, esses redatores, editores e colaboradores de periódicos procuraram, primeiramente, atuar na esfera privada da família. Demonstrando modelos pelos quais a família brasileira deveria seguir, esses homens de letras conseguiram exercer sua influência sobre o seio familiar. Assim como afirma Maria Lúcia Pallares-Burke, em relação à educação no século XIX, no Brasil, não se pode falar apenas de escola, pois existiam outras formas que impactavam no processo educativo:

(...) é, sem dúvida, um erro descrever a educação brasileira do século XIX unicamente em termos de escola, seria igualmente um erro descrevê-la tão-somente em termos de jornais culturais/doutrinários. Há toda uma rede de outros agentes em plena atividade, como o romance e folhetins, por exemplo, que, ao lado de escolas mais ou menos isoladas, competiam pela transmissão dos valores culturais em circulação e que devem ser considerados atentamente se se quiser recuperar, com maior fidelidade, a história da educação brasileira do século passado (PALLARES-BURKE, 1998, p.158).

É dentro deste contexto de popularização da instrução e da educação por meio de diversas práticas, entre as quais a imprensa, que se encontrava a publicação $O$ Sexo Feminino, de Francisca Senhorinha da Motta Diniz. Este periódico é um exemplo de como, a partir de uma perspectiva de vulgarização da educação e da ciência, uma mulher procurou tratar desses assuntos para mulheres. Foi, principalmente na segunda metade do século XIX, que surgiu uma variedade enorme de periódicos voltados para mulheres e dirigidos por mulheres.

Nos estudos sobre a imprensa feminina no Brasil, Dulcília Buitoni é uma das grandes referências a tratar sobre o tema. De acordo com a autora, a imprensa feminina pode ser compreendida a partir de seu público alvo: as mulheres. Portanto, a partir de seu entendimento, independente de quem as produza ou escreva, seja homem ou mulher, o que interessaria seria 
o destino da publicação. O que a definiria seria, portanto, o seu público alvo. Tal como nos termos de Buitoni, "imprensa feminina é aquela dirigida e pensada para mulheres" (BUITONI, 1986, p. 16). A imprensa feminista se diferenciaria da imprensa feminina, pois sua pauta seria, principalmente, a luta por direitos civis e políticos.

Desde o surgimento da imprensa feminina, no século XVII na Grã-Bretanha, assuntos como moda e literatura eram bem recorrentes, o que seria um indicativo, de acordo com Buitoni, de como esta imprensa tratava da questão do novo. Como a moda seria algo que estaria sempre em constante mudança, Buitoni indica como os periódicos femininos procuravam sempre estar atualizados, neste sentido, de modo que os "jornais e revistas femininos funcionam como termômetro dos costumes de época. Cada novidade é imediatamente incorporada, desenvolvida e disseminada" (BUITONI, 1986, p. 24). Aos poucos outras temáticas foram sendo incorporadas por esta imprensa. Decoração, arquitetura, trabalhos manuais, conselhos de saúde, economia doméstica, utensílios domésticos, dicas de beleza, etc., foram muitos dos assuntos tratados pela imprensa feminina.

No caso brasileiro, o primeiro jornal feminino de que se tem notícia é "O Espelho Diamantino", publicado no Rio de Janeiro, em 1827. O segundo é "O Espelho das Brasileiras", publicado em Recife, em 1831. A esses se seguiram outros, editados sob os mais diversos fins. Constância Lima Duarte realizou um levantamento de todos os periódicos femininos publicados no século XIX, dos quais identificou um total de 143 periódicos publicados no Brasil ao longo desse período ${ }^{v}$. Destes, o maior número foi publicado no Rio de Janeiro: 45 periódicos. Se sucedendo no Recife, com 25; São Paulo: 14; Salvador: 9; e Fortaleza: 4.

Entre os assuntos das publicações, a autora constatou uma grande variedade de temas e de estilos, passando por ficções, poesias, crônicas, ensaios, memórias, escritos militantes, conselhos sobre saúde, economia doméstica, etc. A este respeito a autora afirma:

E os periódicos são surpreendentemente múltiplos em sua diversidade. Há os assumidamente feministas; os assumidamente conservadores; os que não se comprometem; os que se limitam as passatempo; os que visam certos segmentos, como a jovem, a mãe de família, a adolescente, a estudante; e os que se dedicam a temas específicos: literatura, educação, política, lazer, moda, humor (DUARTE, 2017:22)

Uma perspectiva relevante para pensar a imprensa feminina no século XIX é a partir de sua relação com a instrução. Por conta do escasso acesso que as mulheres tinham à educação nesta época, a imprensa foi um meio pelo qual muitas mulheres puderam ter acesso à ciência 
de uma maneira geral. Dessa forma, a imprensa também pode ser compreendida neste contexto, como um instrumento pedagógico de (in)formação.

Vários textos e periódicos direcionados à vulgarização da ciência e à educação se destinavam especificamente às mulheres. Estas, enquanto leitoras de periódicos e de livros de vulgarização, pertenciam a determinados segmentos sociais, ou seja, aqueles que detinham algum poder aquisitivo. Neste sentido, de acordo com June Hahner, o status social das mulheres do século XIX era derivado de suas famílias e não de si mesmas, fossem elas esposas ou não de homens que possuíam alguma importância no período. Poucas eram as mulheres da época que possuíam acesso às letras, mesmo as de classe alta eram limitadas nesse quesito. A educação dessas mulheres de classe alta consistia basicamente em assuntos que deveriam ter como finalidade a atuação de mãe e de esposa. Além de aprenderem a ler, também era ensinado a elas aulas como a de costura, e como gerenciar uma casa, por exemplo.

Embora se possa verificar a presença delas, poucas mulheres nesse período se dedicaram ao mundo das letras. Algumas colaboraram em jornais e também assumiram a posição de redatoras. Everton Barbosa demonstra o caso do "Jornal das Senhoras", publicado no Rio de Janeiro entre 1852-1855, que era dirigido por mulheres. Esse jornal era comercializado em estabelecimentos que ficavam localizados na R. do Ouvidor, que era um espaço de grande fluxo feminino ${ }^{\mathrm{vi}}$.

Portanto, nessa época, o acesso das mulheres à educação ainda era limitado, embora possa se verificar, como aponta Maria Helena Camara Bastos que neste período, o surgimento de escolas femininas, e a ampliação do mercado editorial de livros e periódicos, de gabinetes de leitura e de bibliotecas, possibilitaram um aumento do público leitor feminino e masculino ${ }^{\mathrm{vii}}$.

De acordo com Gabriella Lopes, foi regulamentada, no Rio de Janeiro, em 1837 a Lei Provincial que definiu os princípios da instrução primária e secundária, determinando os currículos para as escolas de meninas e meninos ${ }^{\text {viii }}$. Para as meninas, os conteúdos estabelecidos foram os saberes como ler, escrever, contar, história nacional, religião católica, alguns elementos de matemática, e os saberes destinados ao ambiente doméstico. Mesmo que fosse um currículo ainda muito restrito, a possibilidade de escolarização permitiu com que muitas mulheres tivessem acesso aos livros e aos periódicos, e aos poucos foi se formando um público leitor feminino. Por isso, periódicos como A Estação, e o Jornal das Senhoras, entre outros, foram aparecendo impulsionados por temáticas que atraíam o público feminino, como modas e literatura. 


\section{Francisca Senhorinha e O Sexo Feminino}

Francisca Senhorinha da Motta Diniz nasceu em São João del-Rei, Minas Gerais, e faleceu em 30 de outubro de 1910, Rio de Janeiro. Sua formação profissional se deu na área da educação, tendo cursado o magistério para instrução de nível primário. Foi a responsável pela fundação da escola doméstica do Colégio Santa Izabell, que ficava localizado na Rua do Lavradio, Rio de Janeiro. Foi casada com o advogado José Joaquim da Silva, com quem teve duas filhas: Albertina Diniz e Elisa Diniz Machado Coelho.

Francisca Senhorinha teve ampla participação na imprensa do XIX, tendo sido colaboradora no jornal A Estação e redatora de A Primavera e A Voz da Verdade, ambos publicados no Rio de Janeiro. Foi a Principal redatora do periódico O Sexo Feminino. Semanário dedicado aos interesses da mulher.

O Sexo Feminino foi publicado, a princípio, entre 1873-1874 na cidade de Campanha, Minas Gerais. No ano de 1875 este jornal foi transferido para o Rio de Janeiro, no qual passou a ser publicado na cidade pela Typographia Lombaerts \& C. Teve uma pausa em sua publicação e retornou à ativa em 1889, ainda no Rio de Janeiro. Após a proclamação da República, O Sexo Feminino passou a denominar-se $O$ Quinze de Novembro do Sexo Feminino, sendo ainda sua redatora e proprietária Francisca Senhorinha, tendo a colaboração de suas filhas e de diversas senhoras.

O periódico possuía quatro páginas, sendo cada dividida em duas colunas. Seus artigos eram sempre divididos por seções: "O Sexo Feminino", "Collaboração", Litteratura", "Noticiario", "Aviso". O valor da assinatura era $5 \$ 000$ por ano e $2 \$ 500$ por semestre. A partir de 1875, ano no qual o jornal passou a ser publicado no Rio de Janeiro, o preço da assinatura teve um aumento. Por ano passou a custar $10 \$ 000$, por semestre $5 \$ 000$, por trimestre $3 \$ 000$, e por mês $1 \$ 000$. A deste ano passou a ser possível a assinatura em outras províncias, que por ano custavam $2 \$ 000$, por semestre $6 \$ 000$ e por trimestre $3 \$ 500$. O folhetim foi outra mudança notada a partir da transferência do jornal para o Rio de Janeiro, que foi incluído na primeira página de cada número do jornal. No ano de 1889, no primeiro número, o jornal modificou seu subtítulo, que passou a denominar-se "Semanario litterario, recreativo e noticioso. Especialmente dedicado aos interesses da mulher".

O jornal O Sexo Feminino, como já aponta seu subtítulo, semanário dedicado aos interesses da mulher, era uma publicação de periodicidade semanal, cujo principal objetivo era tornar o alcance da educação e da instrução mais acessível para as mulheres. Por meio de artigos que buscavam conscientizá-las a partir de sua condição de submissão na sociedade, a redatora 
do jornal e suas colaboradoras propunham o caminho para a emancipação da mulher, que seria por meio do acesso à educação e instrução, tal como se pode observar no trecho:

Em vez de paes de família mandarem ensinar suas filhas a coser, engomar, lavar, cosinhar, varrer a casa etc., etc., mandem-lhes ensinar a ler, escrever, contar, grammatica da língua nacional perfeitamente, e depois, economia e medicina domestica, a puericultura, a litteratura (ao menos a nacional e portugueza), a philosophia, a historia natural, para coroar esses estudos a instrucção moral $e$ religiosa; que estas meninas assim educadas não dirão quando moças estas tristes palavras: "Si meu pai, minha mãi, meu irmão, meu marido morrerem o que será de mim?!". (O Sexo Feminino. A educação da mulher. O Sexo Feminino. Semanário dedicado aos interesses da mulher, Anno I, n. 1, 7 de setembro de 1873, p. 1).

A partir de textos, como o citado acima, seguindo essa linha de defesa do alcance dos conhecimentos para mulheres, o jornal procurou estruturar seus artigos. A autora do texto buscou enfatizar que a relação de dependência, e mesmo de tutela que as mulheres possuíam em relação aos seus pais e aos seus maridos, poderia ser dissolvida por meio da formação que a educação e a instrução possuiriam em suas vidas.

Dessa forma, de acordo com o pensamento de Francisca Senhorinha, seria apenas a partir do direito ao estudo que as mulheres poderiam se equiparar aos homens e contribuir com a formação da sociedade, pois:

Formem-se as mães de família, que por seu turno vão erguer escolas e collegios, nos campos, nas villas, e nas cidades; que ensinem á mocidade de ambos os sexos os são princípios de uma instrucção moral e religiosa, e a face da sociedade se há de mudar. Mãis de família assim formadas prepararão a mocidade que futuramente possa ornar as diversas carreiras a que pode aspirar um moço ou uma moça desde a mais alta escala social até o mais modesto emprego official.

So há um meio de regenerar a sociedade, de mudar moralmente a face da terra, de emancipar a mulher, de salvar-lhe um futuro - é pela educação e instrucção no collegio, ou no lar domestico por pedagogos da escolha paterna. (O Sexo Feminino. Emancipação da mulher. O Sexo Feminino. Semanário dedicado aos interesses da mulher, Anno I, n. 2, 14 de setembro de 1873, p. 1-2)

Para pensar sobre a discussão da emancipação da mulher no século XIX, se faz necessário ter em vista a compreensão sobre esta ideia no período para não cairmos em anacronismos. Embora Francisca Senhorinha proponha que a mulher por meio da educação e instrução poderia alcançar a emancipação, esta se daria dentro dos parâmetros já concebidos no período. Francisca Senhorinha não questionava a maternidade como dever da mulher. Sua inquietação se daria em torno do julgamento, feito por homens, que esta seria a única função que a mulher poderia exercer. A redatora do periódico comprovava que a inteligência da mulher se equipararia ao do homem e que, portanto, a mulher poderia ter acesso aos mesmos conhecimentos que o homem. 
O apontamento feito sobre a ideia de regeneração da sociedade não se restringia a uma discussão apenas d'O Sexo Feminino. Neste período esta era uma questão que estava muito em voga, devido aos debates travados a respeito da construção da nacionalidade e da consolidação de um Estado nacional. Foram diversos os intelectuais que se engajaram no projeto de construção de uma história nacional e ao buscar determinar o que seria ou não nacional. Manoel Luís Salgado Guimarães indica como as gerações que se sucederam ao movimento de Independência procuraram traçar um perfil que identificasse a "nação brasileira", de modo que procuraram delinear uma identidade própria frente às outras nações do XIX ${ }^{\mathrm{ix}}$.

De acordo com Dominichi Miranda de Sá, pensar sobre questões da nacionalidade brasileira foi o que motivou a geração de 1870 no Brasil. Nesse contexto, reflexões sobre o que era próprio da identidade do país, fez com que muitos intelectuais estudassem a cultura, a raça, a natureza, a literatura e história do país. Frente às outras nações da América ou da Europa, o Brasil também deveria se mostrar como um ambiente no qual o progresso e a educação estavam modificando os aspectos do país. O Brasil, nesta época, buscava "uma equivalência com os padrões ocidentais" (SÁ, 2006, p. 35).

A geração de 1870 sentia-se imbuída pelo desejo de construir uma ideia de nação para o Brasil. Um dos caminhos pelos quais esses intelectuais procuraram pôr essa noção em prática foi a partir da defesa de um melhoramento na educação do país. Por isso, muitos deles sentiramse na obrigação de, a partir de diversos meios, como os periódicos, os livros, as palestras, as exposições, etc., ajudarem na instrução de diversas camadas da população. A educação era vista, por esses homens de letras, como uma maneira de sanar o atraso recebido do passado colonial.

Assim sendo, a discussão sobre maternidade estava envolvida com as questões a respeito da construção da nacionalidade. A criança era considerada o futuro da nação e, por isso, caberia aos seus principais cuidadores - os pais, mas principalmente às mães - uma atenção com sua saúde e desenvolvimento. Medicina e Estado agiram em conjunto para abolirem os hábitos considerados nocivos às crianças. De acordo com Patricia Sanine e Elen Castanheira, a medicalização da família teria se dado por meio da infância, com o intuito de serem implantados novos hábitos nas relações entre pais e filhos ${ }^{\mathrm{x}}$.

No âmbito dos debates, no período, de intelectuais inclusive médicos, sobre pátria e nação, os temas referentes à população e à mortalidade estiveram à tona. Entre estes, a amamentação e a maternidade foram um dos principais. A mãe passou a ocupar outro patamar em decorrência de seu papel ao criar e educar os futuros cidadãos da pátria. Por isso, neste 
contexto, a amamentação, por exemplo, tornou-se um 'assunto de Estado', pois o aleitamento contribuía de maneira positiva para a imagem de um país civilizado.

Isto posto, dá para compreender a razão pela qual a maternidade passou a ser considerada como passo importante para o desenvolvimento da nação brasileira. Sendo assim, portanto, as mães assumiram papel primordial, pois seriam elas as principais educadoras dos futuros cidadãos da pátria.

Muitas mulheres deste período se apropriaram desse discurso, como a própria Francisca Senhorinha, para reivindicar melhoramentos nas condições de vida das mulheres. Seguindo a linha de raciocínio expressada por Francisca Senhorinha no trecho acima citado, para contribuir para a formação dos futuros cidadãos da pátria se fazia necessário o investimento na educação e instrução da mulher. A partir de um lugar de atuação que era considerado, no século XIX, como próprio da mulher - a maternidade -, Francisca Senhorinha buscou apropriar-se desse discurso e conferiu-lhe uma dimensão de atuação pública da mulher, propondo que, pela maternidade, a mulher interviria de modo direto na sociedade.

Sendo a imprensa, neste período, um dos principais meios pelos quais as mulheres procuraram se expressar e difundir suas ideias, foi por meio dela que Francisca Senhorinha procurou denunciar a situação de ignorância e opressão na qual se encontravam as mulheres. A educação e instrução pela escola seria o passo inicial para a transformação na vida da mulher, sendo essa formação iniciada ainda em sua infância. Francisca Senhorinha, com este fim, fundou, juntamente com suas filhas, o Collegio Santa Izabel, o que nos permite comprovar sua dimensão de intelectual mediadora, na medida em que propõe, de forma prática, uma intervenção social. De acordo com Cláudia Maia e Bárbara Figueiredo Souto:

Por meio do programa do colégio, criado por Francisca Diniz e suas filhas Amélia, Albertina e Elisa Diniz, podemos observar que foram mantidas as disciplinas relacionadas à vida doméstica, entretanto, houve uma ampliação do conhecimento oferecendo conteúdos como História, Matemática e Geografia. A manutenção das disciplinas domésticas justifica-se, pois Francisca Diniz acreditava que a maternidade e o cuidado com a família era uma dádiva da mulher, entretanto, tais práticas não inibiam o desenvolvimento intelectual feminino nem a participação das mulheres na vida pública (MAIA; SOUTO, 2016, p. 161).

Dessa maneira, a fundação do Collegio Santa Izabel pode ser compreendida como uma das práticas executadas por Francisca Senhorinha que nos permite afirmar sua dimensão de intelectual do período. Seria pela formação escolar que as mulheres poderiam escolher outros caminhos para além do ambiente doméstico. A formação adquirida na escola lhe conferiria base de atuação para carreiras profissionais. Rejane Meireles Rodrigues nos indica como as 
instituições de ensino podem atuar no sentido de disseminação de projetos e convencimentos das populações sobre comportamentos ${ }^{\mathrm{xi}}$. Por isso, a escola fundada pela redatora de $O$ Sexo Feminino foi um passo importante no sentido de fornecer caminhos para a emancipação da mulher. De acordo com Maia e Souto:

\begin{abstract}
Uma "questão relevante na escrita de Francisca Diniz era a inserção da mulher no mercado de trabalho. Para ela, a profissão mais apropriada à mulher era a carreira do magistério, devido à contribuição que a mulher daria na "regeneração" da sociedade. Entretanto, a mulher não precisava se limitar a lecionar. Ela deveria ter acesso a diversos tipos de carreira, pois suas habilidades eram muitas". (MAIA; SOUTO, 2016, p. 161).
\end{abstract}

Essa ideia de atribuir à figura de Francisca Senhorinha uma dimensão intelectual se deve justamente por sua atuação como professora, escritora e fundadora de um colégio. Por meio dessas práticas, portanto, compreendemos que ela estava atuando e intervindo na esfera pública.

A seção do periódico que selecionamos para análise é intitulada de "Noticiario", e estava presente em todos os números. Nela, é possível verificar fatos que a direção do jornal considerava relevantes para as mulheres da época. Embora seu espaço fosse sempre à última página do jornal, era através desta seção que as leitoras do periódico poderiam se atualizar sobre assuntos como o surgimento de escolas para o sexo feminino, a expansão de profissões para mulheres em diversos lugares do mundo, as impressões de outros periódicos sobre $O$ Sexo Feminino. Portanto, essa seção possuía um papel de grande importância dentro do jornal, pois era ela que demonstrava, na prática, os resultados da educação e instrução para as mulheres.

Em alguns números do jornal, foi dada ênfase, na seção "Noticiario" a uma iniciativa realizada por Miguel Vieira Ferreira, Francisco Rangel Pestana, Henrique Limpo de Abreu e José de Napoles Telles de Menezes, na qual buscava beneficiar as mulheres e outras categorias sociais. Este projeto recebeu o nome de Escola do Povo, como se pode verificar no artigo:

ESCOLA DO POVO - Lemos com prazer o combate de intelligencia que em prol dos direitos da mulher têm travado certos cavalheiros distinctos, cujas prelecções vêm inseridas na Republica. O paiz ainda não ouvio linguagem tão sublime, tão lógica, tão illustrada, qual a com que apparece a escola do povo na corte. Honra e gloria a tão beneméritas intelligencias (Noticiário. O Sexo Feminino. Semanário dedicado aos interesses da mulher, Anno I, n. 2, 14 de setembro de 1873, p. 4).

Todos os fundadores da Escola do Povo assumiam uma postura política que defendia o estabelecimento da República. No texto fundador da instituição, fica evidente o desejo dos fundadores de oferecer uma forma de instrução distinta do ensino oficial. Para eles, o único benefício que traria era ensinar a assinar o nome em cartas e contratos sociais, porém não criaria 
cidadãos aptos a questionar a realidade que o cerca. Dessa forma, o ensino oficial seria degradante para o indivíduo e pernicioso para a pátria.

Agindo no intuito de modificar o cenário no qual o ensino se encontrava neste período, é que Miguel Vieira Ferreira, Francisco Rangel Pestana, Henrique Limpo de Abreu e José de Napoles Telles de Menezes fundaram a Escola do Povo. Esta seria oferecida no formato de cursos, sendo todos eles gratuitos e os professores não remunerados. Os cursos seriam divididos em duas partes: Ensino Primário e Cursos livres. No primeiro, seriam oferecidos conteúdos relativos ao ensino primário; o segundo seria um curso de temática livre e não precisaria de inscrições prévias. Entre estes cursos livres foi oferecido um que recebeu elogios de Francisca Senhorinha. O título do curso era "Estudos relativos á mulher", que foi oferecido por Miguel Vieira Ferreira. Alguns trechos deste curso foram publicados n'O Sexo Feminino e foi editado pela Typographia da Republica, localizada no Rio de Janeiro, em 1873.

"Estudos relativos á mulher" procurou demonstrar a situação de opressão na qual a mulher se encontrava, e buscou expor os direitos e deveres que cabiam à mulher. Miguel Vieira Ferreira justificava o curso afirmando que à mulher competia o papel de regeneradora da sociedade e, portanto, havia a necessidade de instruí-la.

Em um comentário feito pela redatora de $O$ Sexo Feminino ao empreendimento da Escola do Povo, Francisca Senhorinha realizou uma crítica às Conferências Populares da Glória, que eram palestras públicas, iniciadas em 23 de novembro de 1873 sob a coordenação do senador e conselheiro imperial Manoel Francisco Correia. Buscava difundir as ciências e debater temas diversos. Para Francisca Senhorinha, havia uma clara diferença entre as Conferências da Glória e as da Escola do Povo: a primeira era formada por um público seleto, já instruído; a segunda procurava incluir indivíduos que não tinham acesso à instrução. De acordo com Francisca Senhorinha:

Instruir o povo por meio de conferencias é um facto novo em nossa terra, posto que já se haja praticado com proveito na velha Europa e na moderna Nova-Iork.

Não confundão nossas leitoras as conferencias populares da escola do povo com as lições de litteratura (impopulares) pregadas na Gloria para os nobres e sábios habituados a manusear os livros de douradas estantes, e que não carecem da instrução de que precisa o povo. (Noticiário. O Sexo Feminino. Semanário dedicado aos interesses da mulher, Anno I, n. 19, 20 de janeiro de 1874, p. 4).

O tema da formação profissional feminina foi um assunto recorrente na seção "Noticiario". Eram divulgados nomes de professoras que assumiam cargos em escolas, como o de Maria Amelia de Noronha, que fora nomeada para reger interinamente a escola pública de meninas da freguesia do Carmo ${ }^{\text {xii }}$; Henriqueta Adosinda da Costa (1853- ), que em 1873 teve 
a nomeação definitiva para professora pública de meninas da segunda cadeira de instrução primária da cidade de Campanha ${ }^{\text {xiii }}$; Deolinda Florentina de Noronha cuja nomeação foi feita para reger a escola do sexo masculino da freguesia do Carmo de Pouso Alto ${ }^{\text {xiv }}$. Sobre o envolvimento das mulheres magistério, Francisca Senhorinha expressou seu contentamento e procurou instigar as leitoras para que investissem em sua formação:

\footnotetext{
Vemos hoje professoras leccionando em suas cadeiras publicas e particulares suas almnas, a quem distribuem instrucção e educação, e, o que é mais, leccionando já a meninos!

(...)

Pois bem - já que ninguém ousa pôr em duvida a capacidade da mulher para educar - e visto que o próprio governo também por seu turno a considera apta para professora não sómente de meninas, mas até mesmo de meninos, confiando-lhe a regência de taes escolas, fazendo-a dest'arte depositaria de sua confiança official, é occasião, é tempo opportuno para do alto da imprensa clamar e convencer taes professoras de que não se contentem com a instrucção sufficiente para ensinar o $-A B C$ - ; é necessário, é urgente que possuão a maior somma possível de conhecimentos, o que só conseguirão com estudo profundo methodisado. (O Sexo Feminino. A mulher no magistério. O Sexo Feminino. Semanário dedicado aos interesses da mulher, Anno I, n. 4, 27 de setembro de 1873, p. 1-2).
}

Era do interesse de Francisca Senhorinha também demonstrar que em alguns lugares do mundo as mulheres já poderiam receber o grau de doutoras em medicina. A faculdade de medicina de Paris, nesta época, já estava conferindo títulos de doutoras a francesas e estrangeiras; na Rússia, as mulheres acima de 19 anos de idade poderiam frequentar a faculdade; na Suíça, ao todo eram 250 o número de mulheres que já haviam recebido o grau de doutoras em medicina, o que para Francisca Senhorinha seria a expressão da sentença de que "o mundo marcha" xv.

\section{Considerações finais}

Com base no que foi apresentado, pode-se concluir que, influenciada pelo contexto de vulgarização, no qual se procurava tornar o alcance da educação e da ciência para um público amplo, em especial as mulheres, Francisca Senhorinha da Motta Diniz empenhou-se em reivindicar o direito das mulheres ao acesso à educação e à ciência. Por meio da seção "Noticiario" do periódico O Sexo Feminino. Semanário dedicado aos interesses da mulher aqui analisado, foi possível constatar os mecanismos que a redatora do jornal se utilizou para tornar efetivo o alcance da educação e ciência às mulheres. Entre estes, apontamos a estratégia utilizada por Francisca Senhorinha em publicar no "Noticiario" fatos que diziam respeito a este universo educacional, como dados com relação à profissoes, nomeações de professoras, indicação de leituras, e a fundação de um colégio. 
Foi precisamente por identificarmos nesta atuação de Francisca Senhorinha uma dimensão que intervinha na esfera pública, que atribuímos a ela o papel de intelectual mediadora. A sua formação como professora lhe conferiu autoridade para sua atuação na imprensa e para a luta pelo direito à educação e à ciência para mulheres.

\section{Referências}

BARBOSA, E. "Em busca de (in)formação: estratégias editoriais femininas na Corte (18521855)". In: BESSONE, Tânia; RIBEIRO, Gladys; GONÇALVES, Monique de Siqueira; MOMESSO, Beatriz (Orgs.). Imprensa, livros e política no oitocentos. São Paulo: Alameda, 2018.

BASTOS, M. Leituras das famílias brasileiras no século XIX: o Jornal das Famílias (18631878). Revista Portuguesa de Educação, ano 1, v. 15, n. 002, Universidade do Minho, Braga, Portugal, 2002, p. 169-214.

BENSAUDE-VICENTE, B. Splendeur et décadence de la vulgarisation scientifique. Questions de Communication, Les culture des sciences en Europe, 17, 2010.

BUITONI, D. Imprensa feminina. São Paul: Editora Ática, 1986.

DUARTE, C. Imprensa feminina e feminista no Brasil - século XIX. Dicionário ilustrado. Belo Horizonte: Autêntica Editora, 2017.

GAGLIARDO, V. O papel pedagógico dos jornalistas no Rio de Janeiro oitocentista. Intellèctus, ano XIV, n. 1, 2015, p. 127-141.

Imprensa e civilização no Rio de Janeiro Oitocentista. 261 f. Tese

(Doutorado em História). Faculdade de Ciências Humanas e Sociais, Universidade Estadual Paulista "Júlio de Mesquita Filho", Franca, 2016.

GOMES, A.; HANSEN, P. "Apresentação - Intelectuais, mediação cultural e projetos políticos: uma introdução para a delimitação do objeto de estudo". In: GOMES, Angela de Castro et al.(Orgs.). Intelectuais mediadores: práticas culturais e ação política. Rio de Janeiro: Civilização Brasileira, 2016.

GUIMARÃES, M. Nação e civilização nos trópicos: o Instituto Histórico e Geográfico Brasileiro e o projeto de uma história nacional. Caminhos da historiografiav. 1, n. 1, 1988.

HAHNER, J. "Honra e distinção das famílias". In. PINSKY, Carla Bassanezi; PEDRO, Joana Maria (Orgs.). Nova História das Mulheres no Brasil. São Paulo: Contexto, 2018.

LOPES, G. Modos, formas e costumes para a educação feminina nas páginas da Revista Popular - Rio de Janeiro (1859-1862). 165f. Dissertação (Mestrado em História), Programa de Pós-Graduação em História da Faculdade de Ciências Humanas, Universidade Federal da Grande Dourados, Dourados, 2019. 
MAIA, C.; SOUTO, B. "Mulheres em Pauta: a imprensa como território de disputas de imagens e direitos femininos". In: RODRIGUES, Rejane et al. A história na imprensa, a imprensa na história. São Paulo: Paco, 2016.

O Sexo Feminino. A educação da mulher. O Sexo Feminino. Semanário dedicado aos interesses da mulher, Anno I, n. 1, 7 de setembro de 1873, p. 1. Disponível em: <http://memoria.bn.br/DocReader/706868/1>. Acesso em: 7 dez. 2020.

O Sexo Feminino. Emancipação da mulher. O Sexo Feminino. Semanário dedicado aos interesses da mulher, Anno I, n. 2, 14 de setembro de 1873, p. 1-2. Disponível em: <http://memoria.bn.br/DocReader/706868/5>. Acesso em: 7 dez. 2020.

NOTICIÁRIO. O Sexo Feminino. Semanário dedicado aos interesses da mulher, Anno I, n. 2, 14 de setembro de 1873, p. 4. Disponível em: 〈http://memoria.bn.br/DocReader/706868/8>. Acesso em: 7 de dez. 2020.

NOTICIÁRIO. O Sexo Feminino. Semanário dedicado aos interesses da mulher, Anno I, n. 19, 20 de janeiro de 1874, p. 4. Disponível em:

<http://memoria.bn.br/DocReader/706868/76>. Acesso em: 13 jan. 2021.

O Sexo Feminino. A mulher no magistério. O Sexo Feminino. Semanário dedicado aos interesses da mulher, Anno I, n. 4, 27 de setembro de 1873, p. 1-2. Disponível online: <http://memoria.bn.br/DocReader/706868/13>. Acesso em: 9 dez. 2020.

O Sexo Feminino. Semanário dedicado aos interesses da mulher, Anno I, n. 11, 15 de novembro de 1873, p. 3-4. Disponível em: 〈http://memoria.bn.br/DocReader/706868/42>. Acesso em: 11 jan. 2021.

SANINE, P.; CASTANHEIRA, E. Explorando nexos entre a construção social da criança e as práticas de saúde. História, Ciências, Saúde - Manguinhos, Rio de Janeiro, v. 25, n. 1, jan.mar. 2018, p. 199-215.

MOREL, M.; BARROS, M. Palavra, imagem e poder: o surgimento da imprensa no Brasil do século XIX. Rio de Janeiro: DP\&A, 2003.

PALLARES-BURKE, M. A imprensa periódica como uma empresa educativa no século XIX. Cadernos de Pesquisa, n. 104, jul. 1998, p. 144-161.

RODRIGUES, R.. “A educação como projeto político e intelectual pelo jornal Gazeta do Norte em Montes Calros. In: RODRIGUES, R. (Org.). A história na imprensa, a imprensa na história. São Paulo: Paco, 2016.

SÁ, D. A ciência como profissão: médicos, bacharéis e cientistas no Brasil (1895-1935). Rio de Janeiro: Editora Fiocruz, 2006.

VERGARA, M. A Revista Brasileira: a vulgarização científica e a construção da identidade nacional na passagem da Monarquia para a República. Tese (Doutorado em História). Rio de Janeiro: Pontifícia Universidade Católica do Rio de Janeiro, 2003. 


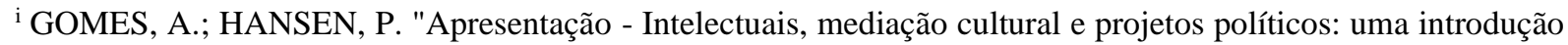
para a delimitação do objeto de estudo". In: GOMES, Angela de Castro; HANSEN, Patricia Santos (Orgs.). Intelectuais mediadores: práticas culturais e ação política. Rio de Janeiro: Civilização Brasileira, 2016.

ii BENSAUDE-VICENTE, B. Splendeur et décadence de la vulgarisation scientifique. Questions de Communication, Les culture des sciences en Europe, 17, 2010.

iii VERGARA, M. A Revista Brasileira: a vulgarização científica e a construção da identidade nacional na passagem da Monarquia para a República. Tese (Doutorado em História). Rio de Janeiro: Pontifícia Universidade Católica do Rio de Janeiro, 2003.

iv GAGLIARDO, V. Imprensa e civilização no Rio de Janeiro Oitocentista. $261 \mathrm{f}$. Tese (Doutorado em História). Faculdade de Ciências Humanas e Sociais, Universidade Estadual Paulista "Júlio de Mesquita Filho", Franca,
\end{abstract} 2016.

v HAHNER, June E. "Honra e distinção das famílias". In. PINSKY, Carla Bassanezi; PEDRO, Joana Maria (Orgs.). Nova História das Mulheres no Brasil. São Paulo: Contexto, 2018.

vi BARBOSA, E. "Em busca de (in)formação: estratégias editoriais femininas na Corte (1852-1855)". In: BESSONE, T.; RIBEIRO, G.; et al. (Orgs.). Imprensa, livros e política no oitocentos. São Paulo: Alameda, 2018. vii BASTOS, M. Leituras das famílias brasileiras no século XIX: o Jornal das Famílias (1863-1878). Revista Portuguesa de Educação, ano 1, v. 15, n. 002, Universidade do Minho, Braga, Portugal, 2002, p. 169-214.

viii LOPES, G. Modos, formas e costumes para a educação feminina nas páginas da Revista Popular - Rio de Janeiro (1859-1862). 165f. Dissertação (Mestrado em História), Programa de Pós-Graduação em História da Faculdade de Ciências Humanas, Universidade Federal da Grande Dourados, Dourados, 2019.

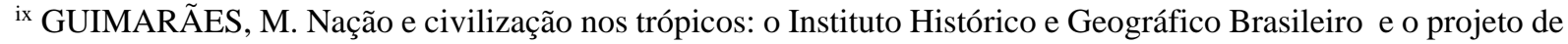
uma história nacional. Caminhos da historiografiav. 1, n. 1, 1988.

x SANINE, P.; CASTANHEIRA, E. Explorando nexos entre a construção social da criança e as práticas de saúde. História, Ciências, Saúde - Manguinhos, Rio de Janeiro, v. 25, n. 1, jan.-mar. 2018, p. 199-215.

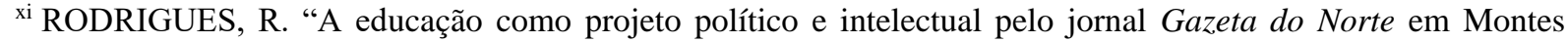
Calros. In: RODRIGUES, Rejane Meireles Amaral (Org.). a história na imprensa, a imprensa na história. São Paulo: Paco, 2016.

xii Anno I, n. 1, 7 de setembro de 1873, p. 4.

xiii Noticiário. O Sexo Feminino. Semanário dedicado aos interesses da mulher, Anno I, n. 3, 20 de setembro de 1873 , p. 4.

xiv Noticiário. O Sexo Feminino. Semanário dedicado aos interesses da mulher, Anno I, n. 10, 8 de novembro de 1873 , p. 4.

${ }^{\mathrm{xv}}$ Variedade. Doutoras em medicina. O Sexo Feminino. Semanário dedicado aos interesses da mulher, Anno I, n. 11, 15 de novembro de 1873, p. 4. 